\title{
Prevalence of Tobacco use and Predictors: A Cross- Sectional Analysis of Baseline Data from Kong Cohort Study in the South of Iran
}

\section{Sakineh Dadipoor}

Hormozgan University of Medical Sciences

Abdul Azim Nejatizade

Hormozgan University of Medical Sciences

Hossein Farshidi

Hormozgan University of Medical Sciences

Abdullah gharibzade

Hormozgan University of Medical Sciences

Teamer Aghamolaei ( $\nabla$ teaghamolaei@gmail.com )

Hormozgan University of Medical Sciences

Shideh Rafati

Hormozgan University of Medical Sciences

\section{Research}

Keywords: prospective Epidemiological Research Studies in IRAN (PERSIAN), cigarette, second-hand smoke, hookah, smoking, predictors

Posted Date: October 7th, 2020

DOl: https://doi.org/10.21203/rs.3.rs-84469/v1

License: (c) (1) This work is licensed under a Creative Commons Attribution 4.0 International License. Read Full License 


\section{Abstract}

Background: Tobacco use (TU) has been increasing in Iran and turned into a major national healthcare concern. Thus, the present research aimed to explore the prevalence of TU and its predictors in Bandar-eKong in the south of Iran.

Methods: The baseline data from Kong cohort study (KCS) were used in a prospective study of 4,035, 4070 year old subjects in Bandar Abbas in Hormozgan Province between 2016 and 2018. Adjusted and crude odds ratios (OR) were used at $95 \%$ confidence interval $(\mathrm{Cl})$ to measure the predictors of TU.

Results: Hookah smoking (HS) showed to be the most prevalent type of smoking (17.60\%, $95 \%$ Cl: 16.41 $18.78 \%)$. Only next was second-hand smoking (17\%, 95\% Cl: 15.81-18.14\%) followed by cigarette smoking (9\%, 95\% Cl: 8.11-9.89\%). Age, gender, education, alcohol consumption and environmental tobacco smoke (ETS) were the main predictors of cigarette and hookah smoking. Marital status, place of residence and psychological problems were the only predictors of $\mathrm{HS}(\mathrm{OR}=.1 .65,95 \% \mathrm{Cl}: 1.11,2.45$, $\mathrm{p}=.01)$, BMI (OR=.95, 95\% Cl: .93, .98, $\mathrm{p}=.002)$ and drug abuse (OR=4.52, 95\% Cl: 3.11, 6.55, $\mathrm{p}<.001)$ were the only predictors of cigarette smoking.

Conclusions: Masculinity, higher age, rural residence, low education, alcohol consumption, drugs, secondhand smoking and history of depression were among the main risk factors of smoking behavior. The results indicated a considerable need for more educational and preventive programs for each risk factor involved in smoking behavior especially for HS, exposure to ETS and its consequences in Kong population.

\section{Introduction}

Tobacco use (TU) is a key general health issue globally and a key risk factor involved in increasing the burden of diseases in the world especially in the case of chronic and non-contagious diseases such as cardiovascular diseases, respiratory diseases, cancer and brain attack [1]. Annually, TU accounts for more than 8 million mortalities worldwide [2]. About $80 \%$ of these mortalities occur in low to average income countries[3] .

In Iran, TU behaviors are ever growing among adults [4] Despite preventive measures, cigarette smoking trend has not reduced among adult population in Iran within the past two decades[5]. According to the CASPAIN study (2011-12), 5.9\% of Iranian adults used tobacco in their lifetime, and this rate is higher than western countries and other middle-eastern countries[6]. HS is another traditional form of TU of an unknown origin. It involves the passage of smoke above water before inhaling. It is termed differently in different countries, including hookah, water-pipe, hubble-bubble, goza and nargile[7, 8]. A body of research has shown that the adverse effects of HS are significantly more than cigarette smoking[9, 10]. Iran has also witnessed an increase in the trend of HS for the past two decades especially in the south of the country[11]. In fact, Hormozgan Province ranks third in terms of the rate of HS[12] . 
In Iran, TU is considered a main healthcare issue which requires major planning with the aim of controlling its use $[13,14]$. There is a considerable need for lowering the burden of HS-related diseases[15], as the current prevalence rate of the behavior is significantly high in Iran[4]. An effective measure before any intervention is the prevention and management of TS through identifying and concentrating on the prevalence of the issue and its correlates. This can help better know the risk factors involved in TS.

Before developing any effective intervention, there is a need for epidemiological investigations aiming to identify the risky behaviors associated with TU[16]. Moreover, there are certain intra- and intergeographical differences in terms of the prevalence of TU[17]. It is essential to conduct independent research in each geographic area marked by idiosyncratic cultural features. In Iran, geographical diversity should be considered carefully in policy-making and preventive TU measures [12].

The present research used baseline data from KCS with the aim of determining the predictors of TU in the target area in Hormozgan province in Iran. In this research, local health staff and policy-makers were provided with the required information to prevent and cut down on TU. Lowering the costs of TU-related chronic diseases and promoting the level of public health and quality of life in the target population were among the long-term goals of the present research.

\section{Research questions}

RQ1: To what extent is TU prevalent in Bandar-e-Kong in the south of Iran?

RQ2: What are the predictors of TU in Bandar-e-Kong in the south of Iran?

\section{Methods}

\section{Design and setting}

The present cross-sectional research used the KCS baseline data in the south of Iran to explore the prevalence of TU and its associated risk factors. Bandar-e-Kong is located in ' $53^{\circ} 54$ to ' $57^{\circ} 54$ to the east and ' $35^{\circ} 26$ to ' $37^{\circ} 26$ to the north at the altitude of 5 meters above Persian Gulf. KCS design and protocol will be described later [18]

In short, KCS is a prospective cohort study already conducted in 2016 with the aim of an epidemiological exploration and identification of the risk factors of noncontagious diseases in Kong in the south of Iran.

The present research was conducted on 4,063 adults, 40-70 years of age who had entered KCS in 201618. The participants were urban residents selected through a multi-stratified sampling (cluster and systematic randomization) among 14 different regions in Bandar-e-Kong. The sampling scope was participants' home. The first building on the right hand side of the nearest street to the center of cohort was selected as the first cluster. Then, from each cluster one region, one street and an alley were selected 
respectively and, afterwards, the participants were selected from each cluster through systematic randomization (list of families). In rural regions, the sampling was done in two stages, the first being a public announcement to invite influential well-reputed neighbors to familiarize them with the benefits and procedures of research. This was done through lecturing in public places such as mosques, distributing pamphlets to introduce the research and putting up posters and banners in villages. The second stage was done by visiting the eligible participants' houses one by one for the interview.

Each interview was held using a questionnaire presented by a well-trained KCS interviewer enquiring about demographic information, several socio-economic indices, history of TU, drug abuse and medical history. The inclusion criteria were explained completely. The participants were supposed to provide a written informed consent to take part in the research. This research was approved by the ethics committee of Hormozgan University of medical sciences (IR.HUMS.REC.159)

\section{Inclusion and exclusion criteria}

The primary inclusion criterion was 40-70 years of age. Only those residing to the target region were included in the study. Immigrants or foreigners could only participate if they had lived in the region for at least a year. For non-immigrants, it was necessary that they resided in the region for at least 9 months. Those who were unwilling to participate despite being told about the research design and benefits as well as those unable to respond to interview questions were excluded.

\section{Instrumentation}

The data collection instrument was a questionnaire developed in the light of the related literature and existing instrument and experiences gained from KCS in Iran or foreign similar works. The reliability and validity of the questionnaire was already approved [18].

The covariates used in this research were as following:

\section{Hookah smoking (HS)}

To find out if the participants had experienced HS, the following question was asked:

Have you ever smoked hookahs in your life?

The responses was supposed to be either yes or no.

\section{Cigarette smoking}

Whether the participants smoked cigarettes or not was checked using the National Health Interview Survey (NHIS). Smokers were defined as those smoking for more than 100 cigarettes during their life. Those who had already ceased smoking were taken as ex-smokers.

\section{Alcohol consumption}


The following question was asked to see whether the participants experienced alcohol consumption or not:

Have you drunk alcohol more than once in your life?"

This question was to be answered as either yes or no.

\section{Drug abuse}

The following question was asked in order to see whether them participants ever experienced drug abuse (e.g. heroin, amphetamine, barbiturates, cannabis, cocaine, hallucinogen, opioid):

Have you ever consumed illicit drugs more than once in life?

This question was to be answered as either yes or no.

Exposure to environmental tobacco smoke (ETS)

This variable was investigated with 2 questions:

Have you been exposed to ETS at home or at work?

How many hours a day have you been exposed to ETS?"

\section{History of depression}

Participants were asked whether they had ever been told by a specialist that they suffered from depression, again to be answered as yes or no.

\section{Demographic variables}

These variables included gender, age, BMI, place of residence, education, occupation, marital status, socio-economic status (possession of accommodation, area of accommodation, number of rooms in accommodation), family size, cigarette smoking by other family members. These were filled out within a questionnaire.

\section{Statistical analysis}

A complete range of information on participants' age, gender, marital status, education, socio-economic status (SES), BMI, place of residence (rural/urban), occupation, spouse's occupation, alcohol consumption, drug abuse, family members' smoking, exposure to ETS at home or work, physical activity, history of depression and psychiatric disorder was collected.

Concerning the low frequency of some levels of independent variables and the high collinearity between the history of depression and other psychiatric disorders, finally, 15 variables were included: age, gender, marital status, education, SES, family size, BMI, place of residence, occupation, alcohol consumption, 
drug abuse, exposure to ETS at home/work, family members' smoking and a history of psychiatric disorders correlating with cigarette smoking and HS.

Chi-squared test was run to test the correlation between two nominal variables. Simple logistic regression was used to estimate crude odds ratio (OR) and independent variables. The significance level was set at .25 in the final model (multiple logistic regression) to calculate ORs.

\section{Results}

A total number of 4,035 people residing in Bandar-e-Kong participated in this study. Their average age was 48.2 years; the majority of the sample was female $(n=2,315,57.4 \%)$. Moreover, $60 \%$ of the sample were illiterate or of a low level of literacy. The majority of women participants were housewives $(n=1,925$, $83.2 \%)$ and their husbands were mostly drivers $(n=210,9.1 \%)$, sailors $(n=178,7.7 \%)$ or unemployed ( $n$ $186,8 \%)$. The majority of men in this study were drivers $(n=189,11 \%)$, fishermen $(n=175,10.2 \%)$ or sailors $(n=157,9.2 \%)$. In this sample, $1,092(27.1 \%)$ used at least one type of tobacco. HS was the most prevalent $(17.60 \%)(95 \% \mathrm{Cl}: 16.41-18.78 \%)$. The next was cigarette smoking ( $9 \%$ of the sample) $(95 \% \mathrm{Cl}$ : $8.11-9.89 \%)$. Table 1 presents a summary of the baseline participants' demographic information. 
Table 1

\begin{tabular}{|c|c|c|}
\hline Continuous variables & Mean & SD \\
\hline Age (yr) & 48.24 & 9.40 \\
\hline Education(yr) & 5.81 & 4.80 \\
\hline BMI & 26.91 & 5.11 \\
\hline Nominal variables & N. & $\%$ \\
\hline \multicolumn{3}{|l|}{ SES } \\
\hline Very Low & 768 & 19.00 \\
\hline Low & 769 & 19.10 \\
\hline Medium & 836 & 20.70 \\
\hline High & 864 & 21.40 \\
\hline Very High & 767 & 19.00 \\
\hline \multicolumn{3}{|c|}{ Age (at the time of participation) } \\
\hline $35-39$ & 931 & 23.1 \\
\hline $40-44$ & 740 & 18.4 \\
\hline $45-49$ & 688 & 17.1 \\
\hline $50-54$ & 549 & 13.6 \\
\hline $55-59$ & 508 & 12.6 \\
\hline $60-64$ & 368 & 9.1 \\
\hline $65-70$ & 242 & 6.0 \\
\hline \multicolumn{3}{|l|}{ Education } \\
\hline$<6$ & 2418 & 60.1 \\
\hline $6-12$ & 1271 & 31.6 \\
\hline$>12$ & 337 & 8.4 \\
\hline Gender (Females) & 2315 & 57.4 \\
\hline \multicolumn{3}{|l|}{ Marital Status } \\
\hline Single & 93 & 2.3 \\
\hline Married & 3605 & 89.5 \\
\hline Widowed or divorced & 328 & 8.1 \\
\hline
\end{tabular}


Though more than $75 \%$ of the sample did not report any experience of smoking cigarettes or hookahs, $6.9 \%$ and $15.5 \%$, respectively, reported smoking cigarettes and hookahs (Table 2 ).

Table 2

\begin{tabular}{|c|c|}
\hline Variables & N. (\%) \\
\hline Neither Cigarette nor Hookah & $3048(75.5)$ \\
\hline Cigarette only & $278(6.9)$ \\
\hline Hookah only & $625(15.5)$ \\
\hline Both Cigarette \& Hookah & $84(2.1)$ \\
\hline
\end{tabular}

Table 3 indicates the distribution of smoking behaviors across genders. On average, the results showed that men began smoking earlier than women (19.02 yrs. Vs. $27.13 \mathrm{yrs}$.). The rate of cigarette and hookah smoking among men was $20.80 \%$ (95\% Cl: $18.90-22.80 \%$ ) and $23 \%$ (95\% Cl: $20.99-25.03 \%$ ), respectively. Besides, the arte of drug abuse and alcohol consumption among men was, respectively, $9.60 \%$ (95\% Cl: $8.28-11.14 \%)$ and $12.40 \%$ (95\% Cl: 10.6-14.04\%).

Table 3

Distribution of smoking types across gender

\begin{tabular}{|lllll|}
\hline variables & Male N(\%) & Female N(\%) & Statistical Test & P value \\
\hline Cigarette & $356(20.80)$ & $6(.30)$ & Chi Square & $<.001$ \\
\hline Hookah & $393(23.00)$ & $316(13.70)$ & Chi Square & $<.001$ \\
\hline Drug abuse & $165(9.60)$ & $10(.40)$ & Chi Square & $<.001$ \\
\hline Alcohol & $212(12.40)$ & $4(.20)$ & Chi Square & $<.001$ \\
\hline ETS (at home) & $141(8.20)$ & $346(15.00)$ & Chi Square & $<.001$ \\
\hline ETS (at work) & $199(11.60)$ & $3(.10)$ & Chi Square & $<.001$ \\
\hline Age at First ${ }^{*}$ Mean(SD) & $19.02(6.58)$ & $27.13(8.25)$ & Simple Regression & .001 \\
\hline * The age of beginning to smoke & & & \\
\hline
\end{tabular}

Among women, the rate of cigarette and hookah smoking was, respectively, .30\% (95\% Cl: .09-.56\%) and $13.7 \%$ (95\% Cl: $12.17-14.99 \%)$. Furthermore, the rate of drug abuse and alcohol consumption among women was .40\% (95\% Cl: .20-.78\%) and .20\% (95\% Cl: .04-.44\%), respectively.

According to Table 4, when other factors are controlled, in the 45-54 year. age group, the odds of cigarette smoking is three times as high as the $>65$ year. group $(\mathrm{OR}=3.05,95 \% \mathrm{Cl}: 1.44-6.44, \mathrm{p}=.003)$. 
Moreover, the odds of cigarette smoking in the 55-64 year. age group is 2.72 times as high as the > 65 year. group $(\mathrm{OR}=2.72,95 \% \mathrm{Cl}: 1.32-5.61, \mathrm{p}=.007)$. 
Table 4

Main predictors of cigarette smoking

\begin{tabular}{|c|c|c|c|c|}
\hline \multirow[t]{2}{*}{ Predictor } & \multicolumn{4}{|l|}{ Cigarette Smoking } \\
\hline & Crude OR $(95 \% \mathrm{Cl})$ & P-value & Adjusted OR (95\% Cl) & P-value \\
\hline Age (yr) & - & - & - & - \\
\hline \multicolumn{5}{|l|}{ Ref: $>65$} \\
\hline $35-44$ & $1.83(.94,3.53)$ & .073 & $1.84(.86,3.96)$ & .11 \\
\hline $45-54$ & $2.98(1.54,5.75)$ & .001 & $3.05(1.44,6.44)$ & .003 \\
\hline $55-64$ & $2.62(1.34,5.12)$ & .005 & $2.72(1.32,5.61)$ & .007 \\
\hline Gender & - & - & - & - \\
\hline \multicolumn{5}{|l|}{ Ref: Females } \\
\hline Males & $101.11(44.99,227.20)$ & $<.001$ & $87.67(34.87,120.37)$ & $<.001$ \\
\hline Education (yr) & - & - & - & - \\
\hline \multicolumn{5}{|l|}{ Ref: Collegiate } \\
\hline$<6$ & $1.32(.82,2.13)$ & .24 & $2.27(1.30,3.95)$ & .004 \\
\hline $6-12$ & $2.20(1.36,3.56)$ & .001 & $1.90(1.12,3.21)$ & .016 \\
\hline Marital Status & - & - & - & - \\
\hline \multicolumn{5}{|l|}{ Ref: Single } \\
\hline Married & $3.27(1.032,10.41)$ & .044 & $1.62(.45,5.82)$ & .45 \\
\hline Widowed or divorced & $.37(.081,1.68)$ & .19 & $1.36(.25,7.39)$ & .72 \\
\hline SES & - & - & - & - \\
\hline \multicolumn{5}{|l|}{ Ref: High } \\
\hline Low & $.97(.76,1.23)$ & .25 & $1.03(.71,1.50)$ & .86 \\
\hline Moderate & $1.05(.77,1.41)$ & .25 & $.89(.63,1.26)$ & .54 \\
\hline Residence Ref: Rural & - & - & - & - \\
\hline Urban & $1.70(1.19,2.42)$ & .003 & $1.40(.92,2.14)$ & .11 \\
\hline Family size & $.98(.93,1.04)$ & .25 & $.95(.88,1.02)$ & .13 \\
\hline Familymembers' smoking & $1.50(1.09,2.06)$ & .013 & $1.21(.74,1.96)$ & .44 \\
\hline BMI & $.91(.88, .93)$ & $<.001$ & $.95(.93, .98)$ & .002 \\
\hline
\end{tabular}




\begin{tabular}{|lllll|}
\hline Predictor & \multicolumn{2}{l}{ Cigarette Smoking } & & \\
\cline { 2 - 5 } & Crude OR (95\% Cl) & P-value & Adjusted OR (95\% Cl) & P-value \\
\hline $\begin{array}{l}\text { Occupation } \\
\text { ref: employed }\end{array}$ & - & - & - \\
\hline Unemployed & $.16(.12, .21)$ & $<.001$ & $1.07(.73,1.57)$ & .69 \\
\hline $\begin{array}{l}\text { Alcohol Consumption } \\
\text { (Ref: non-smoker) }\end{array}$ & $9.89(7.36,13.30)$ & $<.001$ & $2.56(1.79,3.65)$ & $<.001$ \\
\hline $\begin{array}{l}\text { Drug Abuse } \\
\text { (Ref: non-smoker) }\end{array}$ & $16.87(12.21,23.30)$ & $<.001$ & $4.52(3.11,6.55)$ & $<.001$ \\
\hline HS & & & & .07 \\
(Ref: non-smoker) & $1.47(1.13,1.90)$ & .003 & $1.33(.97,1.85)$ & \\
\hline ETS (at home) & $.76(.52,1.09)$ & .13 & $.88(.50,1.53)$ & .65 \\
\hline ETS (at work) & $2.37(1.70,3.29)$ & $<.001$ & $1.79(1.21,2.63)$ & .003 \\
\hline psychiatric disorders & $1.04(.57,1.90)$ & .25 & $1.13(.55,2.31)$ & .73 \\
\hline
\end{tabular}

When the effect of other variables is adjusted, the odds of cigarette smoking among men is nearly 87 times as high as women ( $\mathrm{OR}=87.67,95 \% \mathrm{Cl}$ : 34.87-120.37, $\mathrm{p}<.001)$. The odds of cigarette smoking for those with fewer than 6 years of education and those with 6-12 years of education is, respectively 2.27 and 1.90 times as high as those with an academic degree.

Furthermore, when the other factors are controlled, an increase in BMI for one unit is followed by a decrease in the odds of cigarette smoking for .05 unit $(\mathrm{OR}=.95,95 \% \mathrm{Cl}$. .93-.98, $\mathrm{p}=.002)$. When the effect of other variables is adjusted, the odds of smoking cigarettes is 2.56 times as high in alcohol consumers than non-consumers $(\mathrm{OR}=2.56,95 \% \mathrm{Cl}: 1.79-3.65, \mathrm{p}<.001)$. Moreover, the odds of smoking cigarettes among those exposed to ETS at work is 1.79 times as high as others $(\mathrm{OR}=1.79,95 \% \mathrm{Cl}: 1.21-2.63, \mathrm{p}$ $=.003)$.

According to Table 5, if the other factors are controlled, the odds of HS is 1.57 times as high, in the age group 45-54 yrs. as those above 65 years of age $(\mathrm{OR}=1.57,95 \% \mathrm{Cl}: 1.23,2.01, \mathrm{p}<.001)$. Moreover, the odds of HS is 1.98 times as high for the age group 55-64 yrs. as those above 65 (OR $=1.98,95 \% \mathrm{Cl}: 1.39$, $2.82, p<.001)$. When the effect of other variables is adjusted, the odds of HS for men is 83 times as high as women $(\mathrm{OR}=1.83,95 \% \mathrm{Cl}: 1.33,2.53, \mathrm{p}<.001)$. The odds of $\mathrm{HS}$ for those with fewer than six years of education and those with 6-12 years are 5.57 and 3.92 times, respectively, as high as those with an academic degree. The odds of HS is 2.86 times as high for widowed or divorcees as the single $(\mathrm{OR}=2.86$, $95 \% \mathrm{Cl}: 1.29,6.34, \mathrm{p}=.01)$. Among urban residents, the odds of HS is .24 lower than the rural $(\mathrm{OR}=.76$, $95 \% \mathrm{Cl}: .60, .96, \mathrm{p}=.02)$. The odds of HS is 2.43 times as high for alcohol consumers as non-consumers 
$(\mathrm{OR}=2.43,95 \% \mathrm{Cl}: 1.73,3.42, \mathrm{p}<.001)$. Moreover, the odds of HS for people exposed to ETS at work is 2.27 times as high as others $(\mathrm{OR}=2.27,95 \% \mathrm{Cl}: 1.49,3.44, \mathrm{p}<.001)$. The findings presented in Table 5 indicate that the odds of hookah intake is .65 as high for participants with psychiatric disorders as others $(\mathrm{OR}=1.65,95 \% \mathrm{Cl}: 1.11,2.45, \mathrm{p}=.01)$. 
Table 5

Main predictors of HS

\begin{tabular}{|c|c|c|c|c|}
\hline \multirow[t]{2}{*}{ Predictor } & \multicolumn{4}{|l|}{ Hookah Smoking } \\
\hline & Crude OR $(95 \% \mathrm{Cl})$ & P-value & Adjusted OR (95\% Cl) & P-value \\
\hline Age (yr) & - & - & - & - \\
\hline \multicolumn{5}{|l|}{ Ref: $>65$} \\
\hline $35-44$ & $1.17(.96,1.44)$ & .12 & $1.07(.86,1.34)$ & .53 \\
\hline $45-54$ & $1.91(1.54,2.35)$ & $<.001$ & $1.57(1.23,2.01)$ & $<.001$ \\
\hline $55-64$ & $2.73(2.01,3.71)$ & $<.001$ & $1.98(1.39,2.82)$ & $<.001$ \\
\hline Gender & - & - & - & - \\
\hline \multicolumn{5}{|l|}{ Ref: Females } \\
\hline Males & $1.88(1.60,2.22)$ & $<.001$ & $1.83(1.33,2.53)$ & $<.001$ \\
\hline Education (yr) & - & - & - & - \\
\hline \multicolumn{5}{|l|}{ Ref: Collegiate } \\
\hline$<6$ & $5.48(3.23,9.28)$ & $<.001$ & $5.57(3.18,9.75)$ & $<.001$ \\
\hline $6-12$ & $4.05(2.36,6.95)$ & $<.001$ & $3.92(2.25,6.80)$ & $<.001$ \\
\hline Marital Status & - & - & - & - \\
\hline \multicolumn{5}{|l|}{ Ref: Single } \\
\hline Married & $2.15(1.03,4.47)$ & .039 & $1.39(.65,2.97)$ & .38 \\
\hline Widowed or divorced & $4.20(1.96,9.02)$ & $<.001$ & $2.86(1.29,6.34)$ & .01 \\
\hline SES & - & - & - & - \\
\hline \multicolumn{5}{|l|}{ Ref: High } \\
\hline Low & $1.51(1.19,1.89)$ & $<.001$ & $1.23(.96,1.60)$ & .10 \\
\hline Moderate & $.92(0.72,1.16)$ & .49 & $.83(.64,1.06)$ & .14 \\
\hline Residence Ref: Rural & - & - & - & - \\
\hline Urban & $.76(0.61, .94)$ & .013 & $.76(.60, .96)$ & .024 \\
\hline Family size & $.96(.91, .99)$ & .03 & $.96(.92,1.01)$ & .07 \\
\hline smoking by family members & $1.03(.78,1.34)$ & .25 & $1.08(.78,1.50)$ & .63 \\
\hline BMI & $.97(.96, .99)$ & .012 & $1.01(.98,1.02)$ & .51 \\
\hline
\end{tabular}




\begin{tabular}{|c|c|c|c|c|}
\hline \multirow[t]{2}{*}{ Predictor } & \multicolumn{4}{|l|}{ Hookah Smoking } \\
\hline & Crude OR (95\% Cl) & P-value & Adjusted OR (95\% Cl) & P-value \\
\hline $\begin{array}{l}\text { Occupation } \\
\text { ref: employed }\end{array}$ & - & - & - & - \\
\hline Unemployed & $.79(.67, .93)$ & .005 & $1.05(.82,1.35)$ & .66 \\
\hline $\begin{array}{l}\text { Alcohol Consumption } \\
\text { (Ref: non-smoker) }\end{array}$ & $2.90(2.16,3.89)$ & $<.001$ & $2.43(1.73,3.42)$ & $<.001$ \\
\hline $\begin{array}{l}\text { Drug Abuse } \\
\text { (Ref: non-smoker) }\end{array}$ & $2.18(1.56,3.04)$ & $<.001$ & $1.19(.80,1.76)$ & .37 \\
\hline $\begin{array}{l}\text { Cigarette Smoking } \\
\text { (Ref: non-smoker) }\end{array}$ & $1.47(1.13,1.91)$ & .003 & $1.35(.98,1.85)$ & .06 \\
\hline ETS at home & $1.07(.83,1.36)$ & .24 & $1.19(.89,1.60)$ & .22 \\
\hline ETS at work & $1.72(1.25,2.37)$ & .001 & $2.27(1.49,3.44)$ & $<.001$ \\
\hline psychiatric disorders & $1.52(1.04 .2 .21)$ & .028 & $1.65(1.11,2.45)$ & .013 \\
\hline
\end{tabular}

\section{Discussions}

The KCS data helped to conclude that HS was the most prevalent tobacco type (17.6\%) compared to cigarettes (9\%). Age, gender, education, alcohol consumption and ETS showed to be the main predictors of hookah and cigarette smoking. Marital status, place of residence and psychiatric disorders were predictors of HS only and BMI and drug abuse showed to be predictors of cigarette smoking only.

In the present research, the prevalence of cigarette smoking was .30\% and $20.80 \%$, respectively, among women and men. The overall prevalence was $9 \%$. In their research, Abdollahpour et al. reported the rate of cigarette smoking to be $41.07 \%$ and $32.68 \%$ among women and men, respectively [4]. This reported rate was higher than the present findings. Drope et al. found that $14.2 \%$ of men and .4\% of women were cigarette smokers. This rate among men showed to be lower than the present research, but about women it was consistent with the present findings [19]. The prevalence of HS in the present research showed to be $13.70 \%$ and $23 \%$ among women and men, respectively. The overall rate of HS was found to be $17 \%$. It seems that in the south of Iran, HS is more prevalent than cigarettes, which is consistent with their local culture. Thus, hookah showed to be the commonest tobacco type consumed in this region. It is socially accepted especially among women [20]. In a cross-sectional study in Tehran, the prevalence of HS showed to be $17.6 \%$ among 1,830 participants, which is consistent with the present findings [21]. This is a higher rate than that of adults in the U.S. (.6\%) [22]. and lower than a similar research in Kuwait which reported the prevalence of HS $79.9 \%$ and $21.1 \%$ among women and men, respectively [23]. Different 
geographical contexts and demographic information makes the comparison of information difficult. Yet, the prevalence of hookah and cigarette smoking in the present research was higher than the Iranian national report by Nemati et al. (5.6\% vs. .3\%). The prevalence of exposure to ETS in the present research was found to be $15.1 \%$ and $19.8 \%$ among women and men, respectively. This rate is lower than the works of research by Abdollahpour et al. (4) and Zeng et al[24]. These divergences can be explained partly by the different national rules and regulations in different countries and demographic features.

The logistic regression analysis in the present research showed that masculinity increased the risk of HS for about 1.83 times as high. These findings are similar to the results of other studies in Iran and foreign countries [25-27]. Contrary to the present findings, a body of research showed that the prevalence of HS among women was higher than men $[28,29]$. Another study showed to gender-based difference in the prevalence of HS [30]. These divergent findings can be partly attributed to the idiosyncratic cultural, geographical differences, gender distribution, features of the target population and sample size. It is noteworthy that though in the present research the prevalence of HS is higher among men than women, among women, $\mathrm{HS}$ is significantly more prevalent than consuming cigarettes, alcohol or drugs. The difference showed to be statistically significant. This would point to the fact that HS is more socially acceptable in Bandar-e-Kong population. The results of an extensive survey in 2007 in Iran showed that from among tobacco types (hookah, pipe and cigarette), more than half of women (1.9\% out of $3.2 \%$ ) consumed hookahs among all tobacco types[31]. It seems that HS is rooted in public culture for long in the south of Iran especially in Hormozgan, and has turned into a local cultural value. It is a socially accepted behavior [19]. Thus, public awareness-raising through mass media and enculturation of the adverse effects of HS seems to be essential. HS needs to be considered as a detrimental social behavior as cigarettes and other addictive drugs are.

The present findings showed that tobacco consumption, alcohol consumption and drug abuse are more prevalent among men than women and this divergence showed to be statistically significant. A body of research also reported the higher prevalence among men [4, 32-34]. Internalization of gender roles in participants and sociocultural acceptance of cigarettes and drugs among men can be part of the reason for the higher prevalence of smoking by male population [35]. Contrary to the present findings, another study no difference was found across genders in terms of alcohol consumption and drug abuse[36]. This difference can be partly due to the age range and other idiosyncrasies of the target population and cultural and ethnic differences even within the country. It is further noteworthy that overall at the global scale, men are more prone to detrimental habits than women. The former tend to underestimate the detriments of drug abuse more than the latter [37]. Particularly in more conservative communities, where women are more controlled than men, access to cigarettes, alcohol and drugs is harder for women, and consuming such stuff is deemed culturally unacceptable for women in Islamic countries[38] .

The present research showed that women are more exposed to ETS at home, than men. In some other research, Al-Zabadi et al. in Palestine observed that more than half of the participants admitted that a family member or a spouse also consumed tobacco and they, thus, were exposed to ETS [39]. Contrary to the present findings, Skorge et al[40]., Alamgir Kabir et al[41]. showed that men are more exposed to ETS 
than women. This divergence can be explained by the fact that Skorge et al. and Alamgir Kabir explored ETS at work and public places. Women are mostly housewives and are, thus, less exposed to ETS. Besides, different social and cultural features of different countries can account for such divergences. These findings can be explained by the fact that the sociocultural idiosyncrasies of Iran has led to the higher prevalence of cigarette smoking in men than women[4]. Consequently, those in the vicinity of smokers, primarily women and children, are more exposed to ETS. Raising smokers' and non-smokers' awareness of the adverse effects of ETS at home can be an effective strategy with this concern.

In the present research, men are significantly more exposed to ETS at work than women. This finding is consistent with a body of research by Skorge et al[40]., Alamgir Kabir et al[41]. and Akansha Singh[42]. This would point to the gender-related differences in occupation. Probably a higher percentage of men are employed than women. Thus, it is not far from expectation that men are more exposed to ETS at work. It seems that there is a strong need for smoke-free rules and regulations at work, as it is essential to optimally take care of smokers and non-smokers by providing a smoke-free environment [42].

The present research revealed that the beginning age of smoking cigarettes was lower among men than women. A body of research also reported the same finding[4, 43]. This finding can be explained by men's more freedom of action in family and society and their more active social role. During adolescence and adulthood, the male enjoy more social presence under less supervision. However, the female are more controlled in family, which can be part of the reason for this gender-based difference. A relevant study showed that stricter family control over men is less effective than on women in ceasing alcohol or tobacco consumption and other illicit drugs [44].

Furthermore, the present findings revealed that an increase in age is followed by a decrease in tendency to smoke cigarettes and hookahs. In other words, the young showed a stronger tendency to smoke [25, $45,46]$. Contrary to the present research, another study reported a higher rate of TU at a higher age $[4,47$, 48]. This divergence might be explained by different features of the target populations and the age ranges. Moreover, probably the emergence of diseases following an increase in age and prohibited use and a better understanding of risks associated with drug abuse or other forms of TU lowered the rate of consumption.

As the present findings showed, HS showed to prevail more among widows and divorcees than the single. Some other studies reported similar findings too $(49,50)$. As reported in some work of research, perceived family norms among the married can be effective in intention to cease TU (51). Similarly, in another study, married women showed to be encouraged to cease TU more than the single[20]. This finding can be explained by the fact that widows and divorcees might suffer more emotional and social deficiencies due to their loss than others. Thus, they might have appealed to smoking drugs to relieve their mind.

Another finding was that a higher level of education was associated with less cigarette or hookah smoking. In a similar vein, a body of research showed that lower level of education was a key reason for tendency to illicit drugs $[49,50]$. Contrary to this finding, in some other works of research, higher education showed no protective effect on the rate of TU $[26,51]$. These differences can be partly explained by the 
quality of items within the questionnaire, participants' education level and different sociocultural features. In addition, lower level of education can lower health literacy and then result in unawareness of consequences and actual risks of drug abuse which pave the way for the occurrence and continuation of addictive behaviors [52].

The results also showed that rural residence was a predictor of HS. Another study reported that more than half of rural residents accepted TU at home[53]. Still, some other research reported that rural residence was marked by a twofold rate of cigarette smoking[54]. This higher prevalence can be partly attributed to the existing gap of knowledge in rural areas in comparison to urban counterparts. Another reason might be that tobacco control and regulatory efforts are not implemented as strictly as cities in rural areas[55]. This finding points to the essentiality of greater attention to rural communities as a vulnerable population whole exploring the effective and fair tobacco control and other health-related policies.

The present findings showed that alcohol consumption was a predictor of cigarette and hookah smoking. Other investigations also reported higher chances of hookah and cigarette smoking among alcohol consumers $[4,56]$. Occasionally, alcohol consumption and cigarette smoking develop simultaneously. In other words, it seems that alcohol consumption expose people more to cigarette and hookah consumption. As it was expected, lifetime drug abuse correlated with cigarette smoking[4]. Concerning this, a number of studies pointed to the strong association of the history of cigarette smoking and illicit drugs $[57,58]$. Moreover, exposure to ETS correlated with hookah or cigarette smoking. Probably, those exposed to ETS showed a stronger tendency to TU. In a similar vein, some investigations found exposure to ETS as a factor involved in TU[18,56]. Another explanation might be that those exposed to ETS might become more curious to try smoking [59]. Still, another finding was that psychiatric disorders could predict HS among the participants. Similarly, some other researchers reported the prevalence of HS among people of psychiatric disorders such as depression and stress[4,60]. Furthermore, an increase in BMI was followed by a decrease in the rate of cigarette smoking. Similarly, a body of related research showed that cigarette smokers had a lower BMI than non-smokers. In other words, BMI and cigarette smoking correlated negatively and this correlation was statistically significant [61,62]. Contrary to the present findings, some other research indicated that a higher BMI was accompanied by more chances of beginning to smoke earlier and more frequently[63]. Yet, the cross-sectional nature of the research limits a causal relation claim among drug abuse, alcohol consumption, ETS, psychiatric disorders, BMI and hookah and cigarette smoking. These interrelations still need more longitudinal and in-depth investigations.

\section{Limitations And Strengths}

One limitation of the present research was the self-reporting nature of data collection. Thus, the validity of the data depended to a great extent on the accuracy of participants' responses. However, interviewers tried to emphasize the confidentiality of information and reduce this bias as far as possible. Moreover, this research was conducted on Kong population, which further limits the generalizability of the results. Another key limitation lies in the information about alcohol consumption, drug abuse and TU. In 
information retrieval revealing such information might be faced with the feeling of embarrassment, undervaluation and crime consideration due to the cultural context. Moreover, the present research was population based. No similar research was found to explore the prevalence of TU and its correlates in the target region. The results can provide useful practical information to evaluate and reform tobacco control planning and policy-making in Iran and more specifically in the target region.

\section{Conclusions}

The prevalence of HS and exposure to ETS showed to be above average in the present research. Masculinity, older age, rural residence, low education, alcohol consumption, drug abuse, ETS and history of depression were among the risk factors of smoking behavior. The present findings revealed a great need for more systematic education and preventive measures for each risk factor especially HS, exposure to ETS and its consequences in Bandar-e-Kong. Considering the present contradictions in these findings and the related literature, it seems that more specialized investigations are required to reveal whether any other similar factor accounts for smoking behavior in Iran.

\section{Abbreviations}

HS

hookah smoking

TU

Tobacco use

KCS

Kong cohort study

ETS

environmental tobacco smoke

\section{Declarations}

\section{Acknowledgements}

The present authors wish to express gratitude to the Ministry of Health and Medical Education of Iran for the funding used for the PERSIAN Cohort Study (Grant no. 700/534). The authors also express their gratitude to the participants for their sincere cooperation in this study

\section{Authors' contributions}

Aghamolaei T, designed the study, analyzed the data and reviewed the manuscript.; dadipoor S, designed the study, analyzed the data drafted the manuscript and critically reviewed the manuscript, Nejatizade A; designed the study, reviewed the manuscript, Farshidi H, Ghribzadeh A, reviewed the manuscript, Rafati R, analyzed the data and reviewed the manuscript all authors read and approved the final manuscript. 


\section{Funding}

This study is funded by a research grant from PERSIAN Cohort Study (Grant no. 700/534).

\section{Availability of data and materials}

The datasets used and analyzed during the current study are available from the corresponding author on reasonable le request

\section{Ethics approval and consent to participate}

Ethical approval was received for this study from the Ethics Committee of Hormozgan University of Medicine Sciences (1399.159.IR.HUMS.REC). Subjects provided written consent to participate in the study

\section{Consent for publication}

Not applicable.

\section{Conflict of interest}

The authors declare that they have no conflict of interest.

\section{Authors' information}

1. PhD Student in Health Education and Promotion, Student Research Committee, Faculty of Health, Hormozgan University of Medical Sciences, Bandar Abbas, Iran, 2. MD, PhD, Professor, Department of Medical Genetics, Faculty of Medicine, Hormozgan University of Medical Sciences, Bandar Abbas, Iran, 3.MD Professor of Cardiology, Faculty of Health \& Cardiovascular Research Center, Hormozgan University of Medical Sciences, Bandar Abbas, Iran..4. MD of Cardiology, Tobacco and Health Research center, Hormozgan University of Medical Sciences, Bandar Abbas, Iran 5..Professor of Health Education and Promotion, Cardiovascular Research Center, Hormozgan University of Medical Sciences, Bandar Abbas,6. PhD of Biostatistics, Social Determinants in Health Promotion Research Center, Hormozgan Health Institute, Hormozgan University of Medical Sciences, Bandar Abbas, Iran

\section{References}

1. Gowshall M, Taylor-Robinson SD. The increasing prevalence of non-communicable diseases in lowmiddle income countries: the view from Malawi. Int J Gen Med. 2018;11:255.

2. World Health Organization. Tobacco key facts. Geneva,Switzerland: World Health Organization; 2019. https://www.who.int/news-room/fact-sheets/detail/tobacco..

3. Organization WH. WHO urges more countries to require large, graphic health warnings on tobacco packaging: the WHO report on the global tobacco epidemic, 2011 examines anti-tobacco massmedia campaigns. Cent Eur J Public Health. 2011;19(3):133. 
4. Abdollahpour I, Mansournia MA, Salimi Y, Nedjat S. Lifetime prevalence and correlates of smoking behavior in Iranian adults' population; a cross-sectional study. BMC Public Health. 2019;19(1):1056.

5. Parizadeh D, Momenan AA, Amouzegar A, Azizi F, Hadaegh F. Tobacco smoking: findings from 20 years of the Tehran Lipid and Glucose Study. International journal of endocrinology and metabolism 2018, 16(4 Suppl).

6. Organization WH: WHO report on the global tobacco epidemic, 2017: monitoring tobacco use and prevention policies: World Health Organization; 2017.

7. Yadav S, Rawal G. Waterpipe tobacco smoking: A mini-review. Journal of translational internal medicine. 2018;6(4):173.

8. Muzammil DS, Al Rethaiaa AS, Al Mutairi AS, Al Rashidi TH, Al Rasheedi HA, Al Rasheedi SA. Prevalence and perception of shisha smoking among university students: A cross-sectional study. Journal of International Society of Preventive Community Dentistry. 2019;9(3):275.

9. Sepetdjian E, Abdul Halim R, Salman R, Jaroudi E, Shihadeh A, Saliba NA. Phenolic compounds in particles of mainstream waterpipe smoke. nicotine tobacco research. 2012;15(6):1107-12.

10. Radwan G, Hecht SS, Carmella SG, Loffredo CA. Tobacco-specific nitrosamine exposures in smokers and nonsmokers exposed to cigarette or waterpipe tobacco smoke. Nicotine Tob Res. 2012;15(1):130-8.

11. Danaei M, Jabbarinejad-Kermani A, Mohebbi E, Momeni M. Waterpipe Tobacco Smoking Prevalence and Associated Factors in the Southeast of Iran. Addiction health. 2017;9(2):72.

12. Nemati S, Rafei A, Freedman ND, Fotouhi A, Asgary F, Zendehdel K. Cigarette and Water-Pipe Use in Iran: Geographical Distribution and Time Trends among the Adult Population; A Pooled Analysis of National STEPS Surveys, 2006-2009. Archives of Iranian Medicine (AIM) 2017, 20(5).

13. Sadeghi-Gandomani H, Derakhshanjazari M, Salehiniya H. LETTER TO THE EDITOR: CIGARETTE SMOKING-A THREAT TO DEVELOPMENT IN IRAN. JAMA. 2014;311:183-92.

14. Moazen B, Shokoohi M, Noori A, Rahimzadeh S, Saeedi Moghaddam S, Rezaei F, Lotfizadeh Dehkordi M, Kazemi MR, Jamshidi HR, Pazhuheian F. Burden of drug and alcohol use disorders in Iran: findings from the Global Burden of Disease Study 2010. Arch Iran Med. 2015;18(8):480-5.

15. Ghasemian A, Rezaei N, Moghaddam SS, Mansouri A, Parsaeian M, Delavari A, Jamshidi HR, Sharifi $F$, Naderimagham S. Tobacco Smoking Status and the Contribution to Burden of Diseases in Iran, 1990-2010: findings from the Global Burden of Disease Study 2010. Archives of Iranian Medicine (AIM) 2015, 18(8).

16. Barati M, Hidarnia A, Niknami S, Allahverdipour H. Factors associated with tobacco smoking among male adolescents: The role of psychologic, behavioral, and demographic risk factors. Avicenna $J$ Neuro Psych Physio. 2015;2(1):e27152.

17. Organization WH: WHO report on the global tobacco epidemic 2015: raising taxes on tobacco: World Health Organization; 2015.

18. Poustchi H, Eghtesad S, Kamangar F, Etemadi A, Keshtkar A-A, Hekmatdoost A, Mohammadi Z, Mahmoudi Z, Shayanrad A, Roozafzai F. Prospective epidemiological research studies in Iran (the 
PERSIAN Cohort Study): rationale, objectives, and design. Am J Epidemiol. 2018;187(4):647-55.

19. Drope J, Schluger N, Cahn Z, Drope J, Hamill S, Islami F, Liber A, Nargis N, Stoklosa M: The tobacco atlas. Atlanta: American Cancer Society and Vital Strategies; 2018. In.; 2019.

20. Dadipoor S, Heyrani A, Aghamolaei T, Ghanbarnezhad A, Ghaffari M. Predictors of Hookah Smoking among Women in Bandar Abbas, Southern Iran: A Cross-Sectional Study Based on the Intervention Mapping Protocol. Substance use \& misuse 2020:1-8.

21. Hessami Z, Masjedi MR, Ghahremani R, Kazempour M, Emami H. Evaluation of the prevalence of waterpipe tobacco smoking and its related factors in Tehran, Islamic Republic of Iran. EMHJ-Eastern Mediterranean Health Journal. 2017;23(2):94-9.

22. Grinberg A, Goodwin RD. Prevalence and correlates of hookah use: a nationally representative sample of US adults ages 18-40 years old. Am J Drug Alcohol Abus. 2016;42(5):567-76.

23. Mohammed H, Zhang Y, Newman M, Shell D. Waterpipe smoking in Kuwait. 2010.

24. Zeng J, Yang S, Wu L, Wang J, Wang Y, Liu M, Zhang D, Jiang B, He Y: Prevalence of passive smoking in the community population aged 15 years and older in China: a systematic review and meta-analysis. BMJ open 2016, 6(4).

25. Park SH, Duncan DT, Shahawy OE, Shearston JA, Lee L, Tamura K, Sherman SE, Weitzman M. Analysis of state-specific prevalence, regional differences, and correlates of hookah use in US adults, 2012-2013. Nicotine \& Tobacco Research 2017, 19(11):1365-1374.

26. Soulakova JN, Pham T, Owens VL, Crockett LJ. Prevalence and factors associated with use of hookah tobacco among young adults in the US. Addictive behaviors. 2018;85:21-5.

27. MohammadPoorasl A, Abbasi Ghahramanloo A, Allahverdipour H, Modaresi Esfeh J. Prevalence of Hookah smoking in relation to religiosity and familial support in college students of Tabriz, northwest of Iran. Journal of research in health sciences. 2014;14(4):268-71.

28. Tavafian AGHAMT, Zare SS S: Health related quality of life in elderly people living in Bandar Abbas, Iran: a population-based study. 2010.

29. Shearston JA, Park SH, Lee L, Oshinsky C, Sherman S, Weitzman M. Increasing hookah use among adolescent females in the US: analyses from the 2011-2014 National Youth Tobacco Survey (NYTS). Tobacco Prevention Cessation. 2016;2(September):74.

30. Ferreira MMdSRdS T. MCLdFPR: Tobacco and alcohol consumption among adolescents. Rev Latinoam Enferm. 2010;18(2):255-61.

31. Meysamie A, Ghaletaki R, Haghazali M, Asgari F, Rashidi A, Khalilzadeh O, Esteghamati A, Abbasi M: Pattern of tobacco use among Iranian adult population: results of the national Survey of Risk Factors of Non-Communicable Diseases (SuRFNCD-2007). Tobacco control 2009:tc. 2009.030759.

32. Bakar C, Gündogar D, Ozisik Karaman HI, Maral I. Prevalence and related risk factors of tobacco, alcohol and illicit substance use among university students. The European Journal of Psychiatry. 2013;27(2):97-110. 
33. Bellos S, Petrikis P, Malliori M, Mavreas V, Skapinakis P: Prevalence of Alcohol Use Disorders and Their Association with Sociodemographic Determinants and Depression/Anxiety Disorders in a Representative Sample of the Greek General Population. Psychiatry Journal 2020, 2020.

34. Chinwong D, Mookmanee N, Chongpornchai J, Chinwong S: A comparison of gender differences in smoking behaviors, intention to quit, and nicotine dependence among Thai university students. Journal of addiction 2018, 2018.

35. Karadoğan D, Önal Ö, Kanbay Y. Prevalence and determinants of smoking status among university students: Artvin Çoruh University sample. PloS one. 2018;13(12):e0200671.

36. Mozafarinia R, Assarian M, Ziaaddini A. Prevalence of substance abuse among students of Tehran University of Medical Sciences, Iran. Addiction health. 2017;9(2):103.

37. Liu D, Wang Z, Chu T, Chen S. Gender difference in the characteristics of and high-risk behaviours among non-injecting heterosexual methamphetamine users in Qingdao, Shandong Province, China. BMC Public Health. 2013;13(1):30.

38. Panahi R, Tavousi M, Ramezankhani A, Sahraei M, Osmani F, Khalilipour Darestani M, Rezaee M, Niknami S. Smoking prevalence and its related factors among dormitory students of Shahid Beheshti University of Medical Sciences, Tehran, Iran. Zahedan Journal of Research in Medical Sciences 2018, 20(8).

39. Al Zabadi H, Tarayra A, Ghnima R, Jarar A, Khdor H, Kdarat T. Exposure Evaluation of Environmental Tobacco Smoke: Gender and Socioeconomic Disparities in a Low Income Country-Palestine. Health Science Journal 2016.

40. Skorge TD, Eagan TM, Eide GE, Gulsvik A, Bakke PS. Exposure to environmental tobacco smoke in a general population. Respiratory medicine. 2007;101(2):277-85.

41. Kabir MA, Hossain MM, Duty FA. Patterns, prevalence and determinants of environmental tobacco smoke exposure among adults in Bangladesh. Addictive behaviors reports. 2018;8:113-21.

42. Singh A, Sahoo N. Urban-rural differentials in the factors associated with exposure to second-hand smoke in India. BMJ open 2013, 3(11).

43. Ardeshiri MJ, Moosazadeh M, Masouleh MF, Masouleh MF, Kiani A, Fakhri M. Prevalence of smoking in 15-64 years old population of north of Iran: meta-analysis of the results of non-communicable diseases risk factors surveillance system. Acta Medica Iranica 2013:494-500.

44. Becoña E, Martínez Ú, Calafat A, Fernández-Hermida JR, Juan M, Sumnall H, Mendes F, Gabrhelík R. Parental permissiveness, control, and affect and drug use among adolescents. Psicothema. 2013;25(3):292-8.

45. Hessami Z, Masjedi M, Sharifi H, Emami H, Kazempour M, Jamaati H. Characteristics of Iranian hookah smokers aged 15 and above: a primary report. Health Scope 2016, 5(4).

46. Daou KN, Bou-Orm IR, Adib SM. Factors associated with waterpipe tobacco smoking among Lebanese women. Women Health. 2018;58(10):1124-34.

47. Kassani A, Baghbanian A, Menati R, Hassanzadeh J, Asadi-Lari M, Menati W. Prevalence of cigarette smoking and associated factors among male citizens in Tehran, Iran. Asian Pac J Cancer Prev. 
2016;17(3):1473-8.

48. Jawad M, Nakkash R, Mahfoud Z, Bteddini D, Haddad P, Afifi R. Parental smoking and exposure to environmental tobacco smoke are associated with waterpipe smoking among youth: results from a national survey in Lebanon. Public Health. 2015;129(4):370-6.

49. Bajwa HZ, Al-Turki AS, Dawas AM, Behbehani MQ, Al-Mutairi AM, Al-Mahmoud S, Shukkur M, Thalib L. Prevalence and factors associated with the use of illicit substances among male university students in Kuwait. Medical Principles Practice. 2013;22(5):458-63.

50. ASAYESH H, QORBANI M, SALARY H, MANSORIAN M, SAFARI R. THE RELATION BETWEEN INDIVIDUAL AND FAMILIAL CHARACTERISTICS WITH SUBSTANCE ABUSE TENDENCY, SHORT COMMUNICATION. JOURNAL OF GORGAN UNIVERSITY OF MEDICAL SCIENCES. 2011;12(4 (36)):-.

51. Moosazadeh M, Ziaaddini H, Mirzazadeh A, Ashrafi-Asgarabad A, Haghdoost AA. Meta-analysis of smoking prevalence in Iran. Addiction health. 2013;5(3-4):140.

52. Embleton L, Ayuku D, Atwoli L, Vreeman R, Braitstein P. Knowledge, attitudes, and substance use practices among street children in Western Kenya. Subst Use Misuse. 2012;47(11):1234-47.

53. Kassim S, Rogers N, Leach K. The likelihood of khat chewing serving as a neglected and reverse 'gateway'to tobacco use among UK adult male khat chewers: a cross sectional study. BMC Public Health. 2014;14(1):448.

54. Połtyn-Zaradna K, Zatońska K, Basiak A, Sozańska B, Gaweł-Dąbrowska D, Wołyniec M, Szuba A, Zatoński W: Sociodemographic characteristic of changes in smoking patterns in rural and urban population of PURE Poland study: findings from 6-year follow up. BMC public health 2019, $19(1): 6$.

55. Doogan N, Roberts M, Wewers M, Stanton C, Keith D, Gaalema D, Kurti A, Redner R, Cepeda-Benito A, Bunn J. A growing geographic disparity: rural and urban cigarette smoking trends in the United States. Preventive medicine. 2017;104:79-85.

56. Soule EK, Barnett TE, Curbow BA, Moorhouse MD, Weiler RM. Hookah and alcohol use among young adult hookah smokers: A mixed methods study. Am J Health Behav. 2015;39(5):665-73.

57. Myers MG, Kelly JF. Cigarette smoking among adolescents with alcohol and other drug use problems. Alcohol Res Health. 2006;29(3):221.

58. Shahraki G, Sedaghat Z, Fararouei M. Family and social predictors of substance use disorder in Iran: a case-control study. Subst Abuse Treat Prev Policy. 2019;14(1):17.

59. Dadipoor S, Kok G, Aghamolaei T, Heyrani A, Ghaffari M, Ghanbarnezhad A. Factors associated with hookah smoking among women: a systematic review. Tobacco prevention \& cessation 2019, 5.

60. Hamadeh RR, Al Ansari A, Jahrami H, Al Offi A. Cigarette and waterpipe smoking among adult patients with severe and persistent mental illness in Bahrain: a comparison with the National Noncommunicable Diseases Risk Factors Survey. BMC Res Notes. 2016;9(1):77.

61. Jacobs M. Adolescent smoking: The relationship between cigarette consumption and BMI. Addictive behaviors reports. 2019;9:100153. 
62. Watanabe T, Tsujino I, Konno S, Ito YM, Takashina C, Sato T, Isada A, Ohira H, Ohtsuka Y, Fukutomi Y. Association between smoking status and obesity in a nationwide survey of Japanese adults. PloS one. 2016;11(3):e0148926.

63. Taylor AE, Richmond RC, Palviainen T, Loukola A, Wootton RE, Kaprio J, Relton CL, Davey Smith G, Munafò MR. The effect of body mass index on smoking behaviour and nicotine metabolism: a Mendelian randomization study. Human molecular genetics. 2019;28(8):1322-30. 